\title{
Inteligência competitiva e capacidade de inovação: uma análise de uma indústria de classe mundial no setor automotivo de veículos pesados
}

Frederico Vidigal

\begin{abstract}
Professor Titular do Ibmec Business School e Professor dos Programas de Pós-Graduação da Fundação Dom Cabral. Pesquisador do Núcleo de Marketing e Estratégia (NUME)/Programa de PósDoutorado Cepead/UFMG/ISEG Lisbon School of Economics \& Management
\end{abstract}

Carlos Alberto Gonçalves

Professor Titular da Universidade Federal de Minas Gerais nos Programas Stricto Sensu Cepead/UFMG

Joaquim Ramos Silva

Professor Titular do ISEG Lisbon School of Economics \& Management - Universidade de Lisboa

http://dx.doi.org/10.1590/1981-5344/3176

O presente artigo objetivou analisar a Inteligência Competitiva no contexto da Inovação em uma indústria global do setor automotivo de veículos pesados. Procurouse demonstrar até que ponto a inteligência competitiva tem sido tratada como um driver de inovação, no sentido de provocar mudanças no comportamento de uma empresa, envolvendo o lançamento de produtos e ações de pesquisa e desenvolvimento. Metodologicamente, a pesquisa qualitativa e descritiva utilizou-se de instrumentos de coleta como entrevistas em profundidade com gestores das áreas de "Inteligência Competitiva e de Mercado", "Gestão Comercial e Operações", "Gerência de Produto" da empresa além de pesquisa documental. Como resultados, detectou-se um latente investimento em novos produtos de base tecnológica, oriundos de parcerias com universidades européias, embasadas pela interação entre as atividades de Inteligência Competitiva 
e Inovação. Nesse contexto, ao mesmo tempo em que a indústria analisada demonstra sua busca constante por processos mais ágeis, são relatados processos aplicados no sentido de atingir o maior alinhamento com os mercados atendidos e até a antecipação de movimentos de inovação com base em sustentabilidade e eficiência operacional. Os estudos demonstraram ainda os esforços realizados pela empresa para entender a demanda de consumidores e a busca por informações e relacionamento duradouros com clientes.

Palavras-chave: Inteligência Competitiva, Inovação; Indústria automotiva; produtos; processos.

\section{Competitive intelligence and innovation capability: an analysis of a world class industry in the automotive industry of heavy vehicles}

This article aimed to analyze the Competitive Intelligence in the context of Innovation in a global industry of the heavy vehicle automotive sector. We tried to demonstrate the extent to which competitive intelligence has been treated as a driver of innovation, in the sense of provoking changes in the behavior of a company, involving the launching of research and development products and actions. Methodologically, the qualitative and descriptive research was used of collection instruments such as in-depth interviews with managers of the areas of "Competitive and Market Intelligence", "Commercial Management and Operations", "Product Management" of the company besides documentary research. As a result, we detected a latent investment in new technology-based products, coming from partnerships with European universities, based on the interaction between the activities of Competitive Intelligence and Innovation. In this context, at the same time that the industry analyzed demonstrates its constant search for more agile processes, processes are applied in order to achieve the greater alignment with the markets served and until the anticipation of innovation movements based on sustainability and operational efficiency. The studies also demonstrated the company's efforts to 
understand consumer demand and the pursuit of longterm customer relationships and information.

Keywords: Competitive Intelligence, Innovation; Automotive industry; products; Processes.

Recebido em 01.06.2017 Aceito em 23.05.2018

\section{Introdução}

A inteligência competitiva vem crescendo como uma área de apoio à decisão empresarial. Novos estudos têm sido desenvolvidos pela academia e cresce também o interesse empresarial pelo tema de maneira exponencial, se observado o número de trabalhos acadêmicos e publicações a respeito do tema nos últimos cinco anos.

Em um cenário de acirrada competição, observa-se uma busca maior pelo uso estratégico de informações para a aplicação no ambiente de negócios, gerando assim algum tipo de inovação em produtos, melhoria da performance no mercado e resultados mais consistentes. Normalmente, o processo envolve o monitoramento de eventos a partir da análise da concorrência, acontecimentos externos vistos como variáveis incontroláveis e entendimento do perfil e reação de consumidores. Acredita-se que é natural que a inovação esteja presente dentro do universo da competição, provocando um incremento de vantagens competitivas de empresas que a aplicam em seus produtos e no seu posicionamento de mercado.

Este artigo tem como objetivo "analisar a Inteligência Competitiva no contexto da Inovação em uma indústria, seja envolvendo a antecipação de movimentos da concorrência no sentido de provocar ações mais assertivas no mercado (produtos, serviços, processos mais ágeis e mais alinhados à demanda mutante de consumidores, cada vez mais informados e exigentes) ou mesmo na infraestrutura de empresas que a implementam".

Neste artigo, pretendeu-se, mais especificamente, descrever os resultados de um estudo realizado em uma empresa multinacional que atua no setor automotivo, mais especificamente no setor de veículos pesados para transporte de pessoas e cargas. Trata-se aqui de entender até que ponto a inteligência competitiva tem sido tratada como uma driver de inovação, no sentido de provocar mudanças de comportamento de uma empresa, no lançamento de produtos e nas suas ações de pesquisa e desenvolvimento, muito além de uma postura apenas reativa no ambiente de negócios. Para tanto, utilizou-se como campo de estudo o ambiente industrial automotivo que requer inovação para fins de economia constante e redução de emissão de poluentes.

O artigo abordou também a análise da infraestrutura de Inteligência Competitiva da indústria estudada que possui mais de um século de história e tem sua origem na Europa, possuindo planta industrial e rede de 
comercialização de veículos grande porte no Brasil desde meados do século XX. Utilizou-se como pano de fundo os quatro Ps da inovação.

Nesse sentido, pretende-se com o estudo, responder a seguinte indagação: até que ponto a inteligência competitiva está estruturada e planejada para gerar inovação, seja em "produto, processo, posição ou paradigma"? Para tanto, considerou-se como marco teórico a as contribuições clássicas de Schumpeter $(1934,1997)$ e Bessant e Tidd (2008), diretamente aplicáveis à indústria automotiva. Ao final do artigo, foi construída, no sentido e orientar os resultados, uma análise da eventual relação da inteligência competitiva e inovação a partir das informações coletadas dos representantes da empresa.

Justifica-se a escolha do tema considerando a importância da Inovação no ambiente competitivo. Ao analisar a concorrência e apoiar a decisão, a Inteligência Competitiva demonstra-se apta a orientar processos inovadores na indústria, sobretudo no universo estudado? É o que se pretende atingir como resultados.

\section{Fundamentação teórica}

\subsection{A inteligência competitiva}

A gestão da informação e a construção do conhecimento nas organizações têm transformado o mundo dos negócios e criado vantagens para os empreendedores que a utilizam, pois a diversidade de aspectos do ambiente externo, que necessitam ser monitorados, exige importantes esforços dos líderes, planejadores e tomadores de decisão.

Inteligência é usar a informação de forma eficiente e tomar decisões com uma imagem menos do que perfeita. É ver claramente sua concorrência, compreender a estratégia e agir antecipadamente com esse conhecimento. Se você é o primeiro a ver a imagem claramente, você percebe que está à frente do mercado e de sua concorrência (FULD, 2007, p. 16).

A prática da Inteligência Competitiva permite às organizações o desenvolvimento de uma cultura de busca por informações que, de forma efetiva, subsidiem as suas estratégias. A criação de um sistema de inteligência, envolvendo coleta, tratamento, análise e disseminação da informação sobre atividades dos concorrentes, fornecedores, clientes, tecnologias e tendências gerais dos negócios, vem ao encontro da necessidade de monitorar continuamente o ambiente externo. Segundo Roedel (2002), tais fatores estão direcionados a proporcionar um estabelecimento de uma direção no que tange à estratégia e tomada de decisões "em tempo real".

De acordo com Miller (2002), os dados quando organizados tornamse informação; informações quando analisadas transformam-se em inteligência. Nas empresas, o processo de decisão geralmente determina os objetivos do processo de inteligência. Segundo o autor, a inteligência pode ser empregada em muitas demandas organizacionais como: tomada 
de decisões com vantagem sobre a concorrência; negócios realizados com maior velocidade, aplicações business to business (B2B); redução de custos de estoques; aumento das vendas e promoção de um ambiente de fontes digitais, capaz de impulsionar oportunidades.

O processo de inteligência pode criar vantagem competitiva para as empresas, uma vez que pode dar sustentação a decisões fundamentais em inúmeros departamentos ou setores de uma mesma empresa. A tecnologia da informação e o uso da Internet podem desempenhar um papel importante para fazer de pequenas empresas, empreendimentos altamente competitivos.

\subsection{A inovação em processos, produtos e serviços na indústria}

A inovação refere-se ao crescimento em relação ao mercado de negócios e está relacionada às novas ideias, contudo, não se refere somente à abertura de novos mercados. Ela também está relacionada ao aperfeiçoamento dos mercados que já estão amadurecidos (BESSANT; TIDD, 2008).

O desenvolvimento da inovação não é uma tarefa fácil para as organizações, mas torna-se necessária para aumentar a competitividade. A inovação normalmente engloba riscos e incertezas, pois necessita de recursos muitas vezes escassos, mas o que pode ser realizado são trabalhos em grupo, o que normalmente acontece em empresas de pequeno porte em que esses recursos são mais escassos, assim, trabalhando em conjunto, a chance da inovação acontecer é maior, pois se utiliza de situações para serem testadas (BESSANT; TIDD, 2008).

No que diz respeito à Inovação, outra importante contribuição é a de Cassol, Zapala e Cintra (2017). Para os autores, é possível observar uma tendência de competição global, em que as empresas que buscam inovar são as que tendem a alcançar melhores resultados. As empresas que se tornam mais competitivas são as que mostram uma capacidade de resposta rápida às necessidades do mercado/cliente, que são capazes de inovar e conseguem coordenar recursos internos e externos em busca de vantagem competitiva.

A inovação, seguindo a contribuição clássica e os preceitos de Schumpeter $(1934 ; 1997)$, pode assumir quatro formas: inovação de produto (envolve mudança nas características ou na estrutura dos produtos ou serviços que a empresa oferece), inovação de processo (considera a mudança na forma em que os produtos/serviços são criados e entregues), inovação de posição (trata das mudanças no contexto em que produto/serviços são introduzidos) e inovação de paradigma (referese às mudanças nos modelos mentais subjacentes que orientam o que a empresa faz) (BESSANT; TIDD, 2008)

A inovação pode acontecer conforme a orientação da empresa, isto é, envolve o seu intuito em utilizar a inovação. No atual mercado competitivo, as empresas necessitam de um diferencial que facilite 
alcançar uma posição de destaque no mercado. A capacidade de inovação expõe atributos que uma empresa precisa para ajudar na atividade de inovação, os quais proporcionam à organização a capacidade de aderir com agilidade novos processos e métodos, desenvolver e inserir novos ou melhores produtos, para uma competição mais efetiva em ambientes que se transformam constantemente (BALAN; LINDSAY, 2007).

\subsection{A indústria automobilística}

O setor automotivo tem na montagem de veículos sua principal atividade e caracteriza-se como um oligopólio global, formado por um pequeno número de grandes empresas internacionalizadas, organizadas em diversas aglomerações produtivas em diferentes países. Os elevados ganhos de economia de escala e de aglomeração, dentre outras barreiras à entrada no processo de produção de um automóvel, são fundamentais para a compreensão do comportamento deste mercado.

Tal indústria possui importantes encadeamentos produtivos sobre outros setores. Utilizando-se da contribuição de Casotti e Goldenstein (2008) observou-se que 50\% do total de borracha, $25 \%$ do total de vidro e $15 \%$ do total de aço produzidos no mundo se destinam a essa indústria, em especial. Para movimentar esse setor, mais de 8 milhões de funcionários estão empregados diretamente e, para cada emprego direto, mais de cinco indiretos são gerados, se computados no cálculo o setor de autopeças.

De acordo com Ferraz, Kupfer e Haguenaur (1996) e Casotti e Goldenstein (2008) este setor está em permanente processo de consolidação, sendo frequente as incorporações, fusões, joint ventures e parcerias comerciais das mais diversas naturezas que, de uma forma geral, reafirmam a estrutura de mercado oligopolizado deste setor econômico.

Os estudos realizados por Gabriel et al. (2011) sugerem a importância da Inovação como uma via capaz de levar à competitividade. Os resultados encontrados para o mercado interno sugerem que o sucesso do aumento de vendas de veículos automotores, dentre um conjunto de variáveis testadas por meio do teste de causalidade de Granger, análise de decomposição da variância e regressão, sofreu maior influência dos fatores preço, volume de financiamentos e taxas de juros (operações de crédito com recursos livres referenciais para taxa de juros pré-fixada). No entanto, devem ser levadas em consideração em futuras pesquisas outras variáveis de ordem microeconômica, como marcas, rede de concessórias, serviço pós-venda, dentre outros fatores não destacados no presente artigo.

A seguir, será discutida a metodologia utilizada para a produção e estruturação do presente trabalho.

\section{Metodologia}


Metodologicamente, o artigo originou-se de uma pesquisa qualitativa e descritiva envolvendo o estudo aplicado a uma indústria do setor automotivo com atuação em nível global e planta industrial no Brasil, conforme descrito anteriormente. Como procedimentos de coleta de dados, foram reunidos documentos físicos e eletrônicos (pesquisa documental) além de resultados de entrevistas em profundidade utilizando-se de um roteiro semiestruturado aplicado a gestores das áreas de "Inteligência Competitiva e de Mercado", "Gestão Comercial e Operações", além da "Gerência de Produto", buscando verificar a eventual relação da busca estratégica por informações, preconizada nas ações de Inteligência Competitiva e seus impactos na Inovação em produtos, respectivamente. Para as entrevistas em profundidade, foram explorados os tópicos trabalhados no referencial teórico do presente artigo.

De acordo com Minayo e Sanches (1993), a metodologia qualitativa trabalha com valores, crenças, representações, hábitos, atitudes e opiniões e adéqua-se a aprofundar a complexidade de fenômenos, fatos e processos particulares e específicos de grupos mais ou menos delimitados em extensão e capazes de serem abrangidos intensamente. A pesquisa qualitativa estuda o conhecimento e a prática dos participantes [...] as inter-relações são descritas no contexto concreto e explicadas em relação a este. Para Flick (2002), a pesquisa qualitativa considera que pontos de vista e práticas no campo são diferentes devido às diversas perspectivas subjetivas e ambientes sociais a eles relacionados.

A pesquisa qualitativa utiliza-se do método de entrevistas e normalmente opta-se pelo tipo semiestruturada. Para Queiroz (1988), este tipo de entrevista é uma técnica de coleta de dados que supõe uma conversação continuada entre informante e pesquisador e que deve ser dirigida por este de acordo com seus objetivos. Desse modo, da vida do informante só interessa aquilo que vem se inserir diretamente no domínio da pesquisa. A autora considera que, por essa razão, existe uma distinção nítida entre narrador e pesquisador, pois ambos se envolvem na situação de entrevista, movidos por interesses diferentes. "[...] as entrevistas permitem acesso a parte das informações não confidenciais e não publicadas que estão na lembrança das pessoas, ou arquivadas por elas" (KASSLER, 2002, p. 150).

No que diz respeito à pesquisa descritiva, Gil (2006), analisa que tem como objetivo primordial a descrição das características de determinada população ou fenômeno. Dentre as pesquisas descritivas, Gil (2006) destaca as que têm por propósito estudar as características de um grupo, ou as que pretendem levantar opiniões, atitudes e crenças de uma população ou estabelecimento de relação entre variáveis. Para investigar o processamento e estrutura da atividade de Inteligência Competitiva e sua eventual relação com a Inovação na organização pesquisada, foram elaboradas as seguintes questões: 
Figura 1 - Roteiro semiestruturado de entrevista em profundidade com gestores ligados a IC e Inovação
1) Descreva como funciona a atividade de Inteligência Competitiva (IC) nesta organização.
2) Quais são os objetivos da atividade de IC na sua organização?
3) Na empresa, qual a infra-estrutura existente para IC? (espaço físico; softwares específicos ou não, bases de dados, Datawarehouse (DW), Business Intelligence (BI) entre outros).

4) Do ponto de vista de aplicação, como ocorrem as práticas de IC?

5) Quais são as fontes de informação utilizadas pela atividade de IC? Essas fontes também são utilizadas para Inovação?

6) Quais são os produtos de informação estratégica? (Exemplo:relatórios, clippings, análises) gerados pela atividade de IC e para quem são encaminhados cada um dos produtos de informação?

7) Até que ponto a inovação se aproxima da Inteligência Competitiva? Por exemplo: a informação coletada e aplicada na empresa gera antecipação de movimentos da concorrência? As informações coletas provocam ações mais assertivas no mercado (produtos, serviços, processos mais ágeis e mais alinhados à demanda mutante de consumidores ou mesmo na infraestrutura da empresa)?

8) O modelo de inovação da empresa contempla objetivos alinhados aos (4 Ps de inovação: "produto, processo, posição ou paradigma" (Schumpeter; 1934, 1997; Bessant, 2009)?

\section{Fonte: Elaborado pelo autor.}

Cabe ressaltar que, para a aplicação das entrevistas em profundidade, os entrevistados foram incentivados a falar livremente. $\mathrm{Na}$ oportunidade do tratamento das informações, foram abordados os métodos de Inteligência Competitiva e Inovação empregados na organização estudada. Tais métodos foram mapeados e categorizados de acordo com o contexto único da organização pesquisada, seguindo o pressuposto metodológico de Flick (2002). Na seção a seguir, são detalhadas as respostas oriundas das entrevistas em profundidade.

\section{Apresentação e discussão dos resultados}

Com relação às questões propostas, na fase da coleta de dados foram registrados os seguintes resultados:

1) Descreva como funciona a atividade de Inteligência Competitiva (IC) nesta organização.

É uma área de suporte principalmente à área de vendas de caminhões. Um grande desafio é fazê-la trabalhar mais efetivamente para a área de Serviços. Sua principal atividade tem sido trabalhar com os números de mercado já realizados. Não participa muito do planejamento estratégico e acaba trabalhando sob demanda específica. Está ligada hierarquicamente à uma gerência executiva que responde diretamente para a diretoria geral comercial do Brasil. (Gestor - Inteligência Competitiva e de Mercado) 
2) Quais são os objetivos da atividade de IC na sua organização?

"Analisar o mercado, gerar opções de cenários e recomendações. Contudo, age muito gerando relatórios estatísticos e dando suporte a projetos que envolvam a força de vendas, informação de clientes e outros segmentos relacionados." (Gestor - Inteligência Competitiva e de Mercado)

3) Na empresa, qual a infra-estrutura existente para IC? (espaço físico; softwares específicos ou não, bases de dados, Datawarehouse (DW), Business Intelligence (BI) entre outros).

"Na estrutura do Brasil, temos 6 pessoas. Não temos um suporte de TI adequado ou exclusivo para a atividade de Inteligência Competitiva. Trabalhamos com algumas ferramentas de BI como o COGNOS IBM para cruzamento de dados." (Gestor - Inteligência Competitiva e de Mercado)

4) Do ponto de vista de aplicação, como ocorrem as práticas de Inteligência Competitiva na empresa?

Realizamos análises estratégicas que ocorrem em um nível superior. Recebemos muitas diretrizes já definidas pela matriz. Cada área também acaba por fazer sua parte estratégica, com pouco suporte da área específica IC. Diria também, que parte da inteligência está distribuída em outros departamentos, como Marketing e PréVendas. (Gestor - Inteligência Competitiva e de Mercado)

5) Quais são as fontes de informação utilizadas pela atividade de Inteligência Competitiva? Essas fontes também são utilizadas para Inovação?

"Utilizamos dados econômicos e setoriais, emplacamentos de veículos, contato com equipe de vendas e principalmente, o contato direto com os clientes (que tem sido o foco da empresa nos últimos anos)." (Gestor - Inteligência Competitiva e de Mercado)

A empresa tem como uma das características o diálogo com os clientes e sempre esteve de portas abertas para eles. A empresa está na busca constante pela melhoria de seus serviços, pela adoção das melhores práticas e para estar cada vez mais presente quando necessário, além de ajudar na rentabilidade dos negócios dos seus clientes. (Gestor - Gestão Comercial e Operações)

[...] de acordo com a nossa percepção, a marca vem evoluindo para oferecer, de forma mais ativa, uma rede que atenda as soluções dos clientes de forma personalizada e ainda mais ágil. (Gestor - Gestão Comercial e Operações)

Essa proximidade com os nossos clientes sempre fez parte do jeito de ser $[\ldots]$. Construímos esse relacionamento durante anos ao oferecer produtos e estamos caminhando para consolidar essa posição também nos serviços. Com isso, acreditamos que conseguiremos ajudá-lo a melhorar cada vez mais os seus resultados operacionais. (Gestor- Gerência de Produto) 
No que diz respeito às fontes de informação, foi relatado pela empresa que a capacidade de inovação está ligada às parcerias com universidades.

Podemos dizer que a capacidade de inovação da nossa indústria está aumentando em decorrência de sua contínua colaboração com universidades, instituições de pesquisa, fornecedores, clientes e outros parceiros. Outro importante ativo é ter acesso à rede global de desenvolvimento do Volkswagen Group. (Gestor - Gerência de Produto)

A coleta de dados possibilita à empresa analisar o desempenho dos veículos em uma ampla variedade de condições operacionais. Uma importante fonte de informação relatada é o motorista. Os dados extraídos do relacionamento com esse profissional são utilizados para analisar o comportamento desses profissionais. Nesse sentido, são realizados esforços em pesquisa e desenvolvimento (P\&D) para a elaboração de novos sistemas mais avançados que possam proporcionar uma melhor assistência ao motorista.

A empresa trabalha com "veículos conectados" ${ }^{1}$, o que oferece uma contribuição valiosa para a pesquisa e desenvolvimento (P\&D) da indústria. Com relação à conectividade, os entrevistados relataram que isso ocorre como referência para criar produtos e proporcionar um atendimento mais planejado e antecipado aos usuários. A intenção é que os profissionais de atendimento já estejam prontos para as demandas e necessidades dos negócios de cada cliente, ou seja, pode-se observar uma atitude focalizada na antecipação.

"A intenção é diminuir ao mínimo possível a quantidade de paradas (decorrentes de manutenção), de modo a potencializar cada uma delas e aumentar o benefício para os clientes, realizando diversos procedimentos em cada revisão" (Gestor - Gerência de Produto).

6) Quais são os produtos de informação estratégica? (Exemplo: relatórios, clippings, análises, gerados pela atividade de IC e para quem são encaminhados cada um dos produtos de informação?

Com relação às informações de mercado, a empresa busca conhecer as operações diárias dos clientes. A ideia é que, ao adotar uma postura ativa ao prestar atendimento, o Ponto de venda (PDV) ou o ponto de serviços da empresa (concessionária) esteja ainda mais próximo e disponível para os clientes.

São gerados relatórios que abastecem toda a área comercial. São realizados Clippings pelos funcionários envolvidos da área de inteligência contemplando não só um conjunto de informações internas, mas também externas. Para isso são comprados produtos de informação desenvolvidos por terceiros ou empresas especializadas. (Gestor - Inteligência Competitiva e de Mercado)

\footnotetext{
${ }^{1}$ Solução inovadora da empresa que chega com o objetivo de ajudar o transportador a fazer a gestão da sua frota por meio do uso inteligente de dados do veículo em parceria com a Rede de Concessionárias da marca.
} 
7) Até que ponto a inovação se aproxima da Inteligência Competitiva? Por exemplo: a informação coletada e aplicada na empresa apresenta os movimentos da concorrência? As informações coletas provocam ações mais assertivas a serem implantadas no mercado (produtos, serviços, processos mais ágeis e mais alinhados à demanda mutante de consumidores ou mesmo na infraestrutura da empresa)?

\begin{abstract}
"A empresa investe significativamente em pesquisa e desenvolvimento (P\&D) de nível mundial". (Gestor - Gerência de Produto).

"Um dos nossos lançamentos recentes é visto como os mais recentes avanços na tecnologia automotiva para caminhões pesados e, com extenso desenvolvimento nas soluções aerodinâmicas e no trem de força". (Gestor - Gerência de Produto).
\end{abstract}

Para se ter uma idéia, conforme documentos analisados, a empresa estudada apresentou um número substancial de investimento. Segundo um documento analisado e disponibilizado para acesso, a empresa vem investindo em uma nova geração de caminhões, fruto de mais de 2 bilhões de euros de investimento e dez anos de pesquisa e desenvolvimento (P\&D). Além disso, a tecnologia embarcada nos produtos da empresa tem sido capaz de reduzir o consumo de combustível em média 5\%. Segundo documentos disponibilizados e analisados, 0 caminhão está disponível apenas na Europa e ainda não tem previsão de chegada ao Brasil, pelo menos até o momento de elaboração da presente pesquisa.

8) O modelo de inovação da empresa contempla objetivos alinhados aos 4 Ps de inovação: "produto, processo, posição ou paradigma"?

Sim. A empresa estimula a cultura inovadora, se observadas as bases das suas políticas internas, a fim de garantir as habilidades necessárias para o seu desenvolvimento e crescimento. Internamente, é promovida a geração de ideias para alcançar soluções de transporte mais sustentáveis o que está evidenciado no relato de um dos gestores.

Nós trabalhamos constantemente com o foco em evolução contínua. A inovação é um dos pontos fortes da marca e ela se constrói baseada nas necessidades de transporte de nossos clientes e dos clientes de nossos clientes. É por isso que investimos tanto na proximidade com eles, pois é dessa maneira que estaremos preparados para evoluir, melhorar e atendê-los para entregar rentabilidade em qualquer cenário. (Gestor - Gerência de Produto)

Com relação ao que diz a gerência de produto, a empresa tem consciência que os clientes exigem soluções mais confiáveis e inovadoras. Tais soluções devem ser capazes de maximizar o tempo de vida útil ou o tempo produtivo do veículo.

Depois do nosso lançamento da linha de motores Euro 6 (modelo de ônibus que utiliza combustíveis como biogás e biometano) da empresa, o foco da marca continua sendo a sustentabilidade dos nossos produtos e processos. [...]. Nossos produtos precisam estar 
alinhados a soluções de transporte com baixo nível de emissão. (Gestor - Gerência de Produto)

Com relação aos "novos produtos", a empresa demonstra ampliar seu foco sobre combustíveis alternativos e hibridização. Com relação a "processos", a empresa demonstrou trabalhar com parcerias ou alianças estratégicas para produzir conhecimento, além de trabalhar em conjunto com universidades européias (Instituto de Tecnologia Real KTH e a Universidade Técnica Chalmers, situada na cidade de Gotemburgo, ambas na Suécia). No que diz respeito ao "posicionamento', a empresa que atua em nível mundial, busca se adaptar às soluções globais às necessidades específicas do mercado, ou seja, a responsividade, é realçada na sua preocupação em monitorar as demandas de mercados. Nesse sentido, constatou-se que a empresa vem ouvindo e observando as demandas dos seus clientes com proximidade, fazendo uso de canais físicos e eletrônicos para monitorar a informação, inclusive nas redes sociais, conforme demonstrado na pesquisa.

Vale ressaltar que, tem sido enaltecido pela empresa que um dos seus consumidores vem agindo como um propagador ou embaixador da marca nas redes sociais (NASCIMENTO, 2016). Os achados da pesquisa demonstram que a empresa estudada tem desenvolvido ações para monitorá-lo e incentivá-lo a continuar a gerar mídia espontânea sobre a marca. Tal perspectiva está associada aos "prosumers". ${ }^{2}$

Os recursos de energia e as políticas energéticas variam de um país para outro, e isso significa que a empresa busca um alto nível de flexibilidade, além de oferecer um amplo leque de soluções. Além disso, usa o gerenciamento estratégico de informações para gerar inovações, 0 que sugere uma relação entre Inteligência Competitiva e Inovação.

Estamos buscando utilizar novas ferramentas e estratégias que aumentem a disponibilidade da empresa, oferecendo aos consumidores soluções customizadas, que otimizem as paradas do veículo e evitem desperdícios de tempo e recursos. (Gestor - Gestão Comercial e Operações)

[...] essas paradas poderão ser sinalizadas pelo próprio caminhão, que passará a calcular quando é a melhor hora de realizar cada módulo de manutenção. O mundo está cada vez mais rápido e conectado, a empresa usará essa tendência e esses recursos para ajudar o cliente na gestão de suas operações logísticas (Gestor Gestão Comercial e Operações).

\section{Considerações finais}

Este artigo teve como objetivo analisar a Inteligência Competitiva no contexto da Inovação em um contexto industrial. Para tanto, tomou-se como ambiente de pesquisa uma indústria automotiva, mais

\footnotetext{
2 Trata-se de um indivíduo na sociedade em rede, apto a utilizar ferramentas disponíveis para tornar-se também produtor de conteúdo. O ciclo contínuo entre os papéis de emissor e receptor de uma mensagem Ihe confere, então, a simultaneidade entre produção e consumo, ou seja, os "producers and consumers"geram os "prosumers".
} 
especificamente a produção de caminhões. Como pergunta orientadora, procurou-se aqui responder até que ponto a inteligência competitiva está estruturada e planejada para gerar inovação, seja em "produto, processo, posição ou paradigma", tomando por base os pressupostos teóricos explorados na literatura. Foram ouvidos os gestores da planta industrial no Brasil e reunidos documentos físicos e eletrônicos (pesquisa documental) além de resultados de entrevistas em profundidade com gestores da empresa das gerências de áreas como "Inteligência Competitiva e de Mercado", "Gestão Comercial e Operações", além da "Gerência de Produto", buscando verificar a eventual relação da busca estratégica por informações, preconizada nas ações de Inteligência Competitiva e seus impactos na Inovação em produtos, processos ou posicionamento da empresa, respectivamente.

Foi possível concluir que a empresa possui atividades de Inteligência Competitiva que envolvem o planejamento, porém não foi possível identificar uma maior consistência das ações, tomando por base os relatos dos respondentes. $O$ processo de Inteligência Competitiva ainda demonstra uma nítida dependência da matriz da empresa na Suécia. Algumas das evidências contidas nos relatos dos gestores da área demonstram uma característica mais reativa do que antecipativa, dos esforços de Inteligência Competitiva da empresa. Nesse sentido, foi possível concluir que o modelo de Inteligência Competitiva aliado à inovação ainda denota alguma fragilidade, porém percebe-se que a atividade encontra-se em fase de construção na planta industrial do Brasil. No entanto, a preocupação da empresa em relação à Inovação, vista separadamente, se mostrou mais expressiva e com características de maior maturidade.

Durante as entrevistas, o conteúdo evidenciou uma tendência a inovação em produtos e serviços ao consumidor, no sentido de ampliar, construir ou manter vantagens competitivas e monitoramento do mercado para o aprimoramento contínuo, embora a empresa já ocupe uma posição definida e até privilegiada no seu competitivo segmento de atuação. Concluiu-se que há, claramente, uma preocupação ambiental e o foco em processos relacionados a emissão de gases, economia em combustível, previsibilidade e eficiência operacional dos produtos. Em novos mercados e segmentos com condições operacionais distintas, a empresa demonstra priorizar a adaptação dos produtos existentes às necessidades locais, o que se compreende como "responsividade", conforme explicitado anteriormente, no presente artigo. Por exemplo: as distâncias de percurso específicas de uma região ou utilização de capacidade podem ser utilizadas para direcionar o desenvolvimento de novos produtos.

A parceria com duas universidades denota 0 foco em desenvolvimento de produtos inovadores e preconiza um alinhamento com a pesquisa e desenvolvimento (P\&D). A empresa ressalta a característica de "conectividade" dos seus produtos como uma forma de estabelecer o monitoramento dos produtos de acordo com as características dos seus mercados consumidores. 
No que diz respeito aos 4P's da Inovação, ainda procurando responder a pergunta orientadora do presente trabalho, os resultados demonstraram também um latente investimento em novos produtos com base tecnológica. Justamente, nesse sentido, nota-se a interlocução entre as atividades de Inteligência Competitiva e Inovação. Nesse contexto, ao mesmo tempo em que a indústria analisada demonstra sua busca constante por processos mais ágeis, são relatados os processos aplicados para atingir o maior alinhamento com os mercados atendidos e até a antecipação de movimentos. Um exemplo disso é a atenção empreendida para entender a demanda mutante de consumidores, evidenciado na busca sistemática por informações advindas de clientes e relacionamentos duradouros construídos entre motoristas de transportadoras e a fábrica.

Finalmente, concluiu-se também, com base no conteúdo relatado pelos gestores e o conteúdo identificado nos documentos disponibilizados e analisados que a empresa se refere aos consumidores como seres cada vez mais "informados e exigentes" e enxerga-os como fontes de informação para fins antecipação, desenvolvimento e aprimoramento de produtos e serviços. Nesse quesito as temáticas "Inteligência Competitiva e Inovação" encontram-se em sinergia consolidando na empresa uma maior capacidade de atingir níveis mais altos de maturidade, embora a Inovação esteja, separadamente, mais desenvolvida em termos de planejamento e ações efetivas.

Como contribuições para estudos futuros, sugere-se que outros trabalhos enfoquem o "grau de maturidade entre o uso combinado de práticas de Inteligência Competitiva e a efetividade da Inovação" passível de ser mapeada, conferindo importância ao monitoramento sistemático de informações de mercado advindas de consumidores e seus reflexos na capacidade de inovação, seja ela disruptiva ou adaptativa, no sentido de construir e manter vantagens duradouras para a competição.

\section{Referências}

BALAN, P; LINDSAY, N. Developing innovation capability measures for the services sector: an exploratory study. Melbourne, Australia: Australian Graduate School of Entrepreneurship Research Report, 2007.

BESSANT, J.; TIDD, J. Gestão da inovação. São Paulo: Bookman, 2008.

BESSANT, J.; TIDD, J. Inovação e empreendedorismo. São Paulo: Bookman, 2009.

CASOTTI, B. P. GOLDENSTEIN, M. Panorama do setor automotivo: as mudanças estruturais da indústria e as perspectivas para o Brasil. BNDES Setorial, Rio de Janeiro, n. 28, p. 147-188, set. 2008.

CASSOL, A.; ZAPALAI, J.; CINTRA, R. F. Capacidade absortiva como propulsora da inovação em empresas incubadas de Santa Catarina. Revista Ciências Administrativas, v. 23, n. 1, p. 9-41, 2017. 
FERRAZ, J.C.; KUPFER, D.; HAGUENAUER, L. Made in Brazil: desafios competitivos para a indústria. Rio de Janeiro: Campus, 1996

FLICK, U. Entrevista episódica. In: BAUER, M. W.; GASKELL, G. (Org.). Pesquisa qualitativa com texto, imagem e som: um manual prático. Petrópolis: Vozes, 2002.

FULD, L. M. Inteligência competitiva: como se manter à frente dos movimentos da concorrência e do mercado. Rio de Janeiro: Elsevier, 2007.

GABRIEL, L. F. et al. Uma análise da indústria automobilística no brasil e a demanda de veículos automotores: algumas evidências para o período recente. $2011 . \quad$ Disponível em: $<$ https://www.anpec.org.br/encontro/2011/inscricao/arquivos/0004d87ea200247ecc320a7f5cc7ca6e2c.pdf > . Acesso em: mar. 2017.

GIL, A. C. Métodos e técnicas de pesquisa social. 5. ed. São Paulo: Atlas, 2006.

KASSLER, H. Recursos de informação para a inteligência. In: MILLER, J. P. O milênio da inteligência competitiva. Porto Alegre: Bookman, 2002.

MILLER, J. P. O milênio da inteligência competitiva. Porto Alegre: Bookman, 2002.

MINAYO, M. C. S.; SANCHES, O. Quantitative and qualitative methods: oppositionor complementarity? Cad. Saúde Pública, Rio de Janeiro, v. 9, n. 3, p. 239-262, jul/sep, 1993.

NASCIMENTO, R. Scania: rei da estrada. São Bernardo do Campo: Scania Brasil, 2016

QUEIROZ, M. I. P. Relatos orais: do "indizível" ao "dizível". In: VON SIMSON, O. M. (Org.). Experimentos com histórias de vida (Itália-Brasil). São Paulo: Vértice; Editora Revista dos Tribunais; Enciclopédia Aberta de Ciências Sociais, 1988. v .5, p. 68-80.

ROEDEL, D. Estratégia e inteligência competitiva. In: MILLER, J. P. 0 milênio da inteligência competitiva. Porto Alegre: Bookman, 2002.

SCHUMPETER, J. A. The theory of economic development. Cambridge, MA: Harvard University Press, 1934.

SCHUMPETER, J. A. Teoria do desenvolvimento econômico: uma investigação sobre lucros, capital, crédito, juro e ciclo econômico. São Paulo: Nova Cultural, 1997. 